\title{
Gallbladder Diseases in Rural India with Special Emphasis on Etiology and Risk Factors
}

\author{
Authors \\ Cyrus Dara Jokhi, Sujata R. Kanetkar, Nikita Vohra \\ KIMSDU, Karad
}

\section{Introduction}

As the cholesterol was considered as major etiological factor in formation of gallstones, gallbladder diseases were considered to be diseases of western world. In UK the prevalence of gallstones at the time of death is estimated to be $17 \%$ and may be increasing ${ }^{1}$. The rate is little lower in African and Indian women which is estimated to be $3-5 \%$. But because of westernization of life style incidence of gall stones is increasing in India not just in urban areas but also in rural areas as well. Gall stones are seven times more common in North than in South India ${ }^{2}$. Gall stones are believed to be etiological factor for acute calculus cholecystitis $(90 \%$ cases of acute cholecystitis) and chronic calculus cholecystitis (95\% cases of chronic cholecystitis) .Gall stones are also responsible for some cases of acute pancreatitis $^{3}$. In fact the gall stones are frequently present $(88-95 \%)$ in patients of gall bladder carcinoma.

\section{Aim and Objectives}

To study risk factors and etiology in cholecystectomy specimens.

\section{Materials and Methods Source of Data}

The present study includes prospective cases of two years from June 2015 to May 2017 and also includes cases from retrospective archival of data of two and half years i.e. - Jan 2013 to May 2015. Thus it includes 130 cases of cholecystectomy specimens during Jan 2013 to June 2017.

\section{Inclusion Criteria}

All Cholecystectomy specimens received in the Department of Pathology in our institute during Jan 2013 to June 2017.

\section{Exclusion Criteria}

There is no exclusion criterion in this study.

\section{Method of Data Collection}

The specimens were collected in $10 \%$ formalin following scrutiny of the patient details and identity. The specimens of cholecystectomy were fixed in formalin for 12-24 hours. Gross examination of all the specimens were done. Bits from one representative full-thickness section from the fundus, one through the body, one through neck of the gallbladder, and one cross section of the cystic duct margin were taken. Additional sections were taken when focal lesions 
were present. These were followed by routine paraffin processing.

\section{Observations and Results}

Out of these 130 cases, in 129 (99.23\%) cases gall bladder was surgically resected as a therapeutic measure for clinically suspected cholecystitis and in remaining only 1 case $(0.77 \%)$ gall bladder was removed with Pancreaticoduodenectomy.

Out of 130 cholecystectomy, 111 were laproscopic and 19 were open laprotomy cholecystectomy.

Out of 19 open laprotomy procedures, 2 procedures were initially started as laproscopic cholecystectomy and were converted into open procedures as gall bladders having necrotizing cholecystitis got ruptured during procedure.

Maximum numbers of patients were in the age group of $41-50$ years $(26.1 \%)$ followed by $51-60$ years $(20.8 \%)$ and $61-70(18.4 \%)$ years.

Mean age of the patient was 50 years. Oldest patient was 80 years, and the youngest was 17 years of age.

Out of total 130 cases, 69 (53\%) were female and $61(47 \%)$ were male. Females were common in age group of 31 to 60 years. After 60 years male patients were more common.

Out of total 130 patients, 126 (96.92\%) patient were nonvegeterian and $4(3.08 \%)$ patients were vegeterian.

Total 51 (39\%) patients used to have food for 3 or more times a day, and $79(61 \%)$ patients used to have food for only 2 times a day.

In the present study most of the patients (95\%) were adults (above 21 years), and among them, $80 \%$ patients were above $60 \mathrm{~kg}$ weight. Mean weight of patients was $71 \mathrm{~kg}$. Minimum weight of patient was $49 \mathrm{~kg}$. Maximum weight was $91 \mathrm{~kg}$.

Average BMI in this study was $26.75 \mathrm{~kg} / \mathrm{m}^{2}$. Average BMI in study for gallbladder diseases patients was higher than average BMI of normal population which is statistically significant by higher odds ratio (1.21).

Out of 130 total patients 18 patients (13.84\%) had diabetes, so presence of diabetes as risk factor in gall bladder disease is statistically significant by higher odds ratio (2.66).

Out of 130 total patients 20 patients (15.3\%) were having history of chronic alcohol consumption, among 20 patients having history of chronic alcohol consumption 12 had pigment stone, $6 \mathrm{had}$ mix stone and in 2 patients gallbladder was acalculous.

\section{Discussion}

The findings of age and sex distribution is in concordance with studies of Daniel Mønsted Shabanzadeh et $\mathrm{al}^{4}$, Vikash Talreja et $\mathrm{al}^{5}$, YenChun Chen et $\mathrm{al}^{6}$, and Tadashi Terada ${ }^{7}$.

Gall bladder diseases are common in nonvegetarian than in vegetarian patients.In present study $96.9 \%$ patients were non-vegetarian, finding is in concordance with study of Pradhan $\mathrm{SB}$ et $\mathrm{al}^{8}$ and Mima Maychet Sangma et $\mathrm{al}^{9}$.

Table No.-1 Comparison of BMI with other Study

\begin{tabular}{|l|c|}
\hline Study & $\begin{array}{c}\text { Odds ratio } \\
\text { (for BMI }>\mathbf{2 5} \mathbf{~ k g} / \mathbf{m}^{\mathbf{2}} \text { ) }\end{array}$ \\
\hline Festi D et al. , 2008. & 1.07 \\
\hline $\begin{array}{l}\text { Muhammad Rizwan Khan et al, } \\
2011 .\end{array}$ & 1.10 \\
\hline Wegene Borena et al , 2014. & 1.94 \\
\hline Yen-Chun Chen et al , 2014. & 1.05 \\
\hline Present study, 2017 & 1.21 \\
\hline
\end{tabular}

In study done by Shaffer EA and Small $\mathrm{DM}^{10}$ average weight of patients was $74.7 \mathrm{~kg}$, which is in concordance with the present study.

Present study finding of high BMI in gallbladder disease patients is in concordance with study of Yen-Chun Chen et $\mathrm{al}^{6}$, Festi $\mathrm{D}$ et $\mathrm{al}^{11}$, Muhammad Rizwan Khan ${ }^{12}$ et al and Wegene Borena et $\mathrm{al}^{13}$.

Table No-2 Cholecystectomy Patients Having Diabetes: Comparison with other studies

\begin{tabular}{|l|c|c|}
\hline Study & $\begin{array}{c}\text { Percentage of } \\
\text { diabetic patients }\end{array}$ & $\begin{array}{c}\text { Odds } \\
\text { ratio }\end{array}$ \\
\hline Festi D et al. , 2008 & - & 2.72 \\
\hline Wegene Borena et al , 2014. & - & 5.38 \\
\hline Yen-Chun Chen et al , 2014 & - & 1.46 \\
\hline Yaser Froutan, 2015 & - & 2.63 \\
\hline Sharma et al, 2017 & - & 1.035 \\
\hline Byung Hyo Cha et al, 2017 & - & 0.73 \\
\hline Present study,2017 & $13.84 \%$ & 2.66 \\
\hline
\end{tabular}


Present study noted increased incidence of gallbladder diseases in diabetic patients. Findings are in concordance with study of Festi D et $\mathrm{al}^{11}$; Yaser froutan ${ }^{14}$, Wegene Borena et $\mathrm{al}^{13}$ and YenChun Chen et $\mathrm{al}^{6}$. Thus there exists statistically significant relationship of diabetes as an etiological factor in gall bladder disease.

Diabetic patients seem to have an increased incidence of gallstones and gall bladder diseases .These are primarily related to fatty infiltration of the liver, obesity associated with type 2 diabetes and not to the diabetes itself. Obesity leads to secretion of bile by the liver that is supersaturated with cholesterol, leading to crystallization and stone formation ${ }^{14}$.

According to the study done by Mugharbel KM et $\mathrm{al}^{15}, 76 \%$ of type II diabetic patients are overweight and obese. Yaser froutan ${ }^{14}$ in his study observed 24(64\%) out of 37 patients with gallstones were having fatty liver and 7 (19\%) patients were having hyperlipidemia, and $8(22 \%)$ patients were having diabetes.

Table No- 3. Cholecystectomy Patients Having History of Chronic Alcohol Consumption: Comparison with other Studies

\begin{tabular}{|l|c|c|}
\hline Study & $\begin{array}{c}\text { Percentage of } \\
\text { patients with history } \\
\text { of chronic } \\
\text { alcoholism }\end{array}$ & $\begin{array}{c}\text { Odds } \\
\text { ratio }\end{array}$ \\
\hline $\begin{array}{l}\text { Yen-Chun Chen } \\
\text { et al, 2014 }\end{array}$ & - & 7.85 \\
\hline $\begin{array}{l}\text { Byung Hyo Cha } \\
\text { et al, 2017 }\end{array}$ & - & 0.24 \\
\hline Present study & $15.3 \%$ & 4.86 \\
\hline
\end{tabular}

Out of 130 total patients 20 patients were having history of chronic alcohol consumption. Ratio is statistically significant; proving role of alcohol as a causative factor in occurence of gall bladder disease; and this finding is in concordance with the study of Yen-Chun Chen et $\mathrm{al}^{6}$. Study done by Byung Hyo Cha et $\mathrm{al}^{16}$ shows that there is decrease in incidence of gall stone formation if person consumes alcohol.

In the present study $60 \%$ patients having history of chronic alcohol consumption had pigment stones. The odds ratio was 85.71. Similar study done by Wayne H. Schwesinger ${ }^{17}$ also showed increased percentage of pigment stones in gallbladder disease with positive alcohol history. After causing chronic liver disease, alcohol as an etiological factors is responsible for gall stone formation as it alters composition of bile ${ }^{18}$.

Studies done by Modaine $\mathrm{P}$ et al, and Masui $\mathrm{H}$. et al observed that alcohol stimulates gall bladder emptying, while study done by Ugwu AC et al noted no significant difference in the gallbladder motility between alcohol drinkers and nondrinkers. So moderate alcohol ingestion does not stimulate gallbladder motility and therefore should not be indicated for the prevention or treatment of cholelithiasis or biliary dyskinesia ${ }^{18}$. So alcohol has controversial relationship as etiological agent in causing gallbladder disease according to different studies, but it has very strong association in causing pigment gallstones .

In 20 patients with history of chronic alcohol consumption, tests like high CRP level, ESR and elevated neutrophil count with ultrasonographic evidence of stone in gallbladder ${ }^{19}$ helped in addition to liver function tests to differentiate, whether derangement of liver function test was due to chronic alcohol consumption or due to attack of cholecystitis, as liver function test gets deranged in both the conditions ${ }^{20}$.

Clinically presence of Murphy's sign can also help in diagnosis of cholecystitis in chronic alcohol consumer patients.

\section{Summary}

- The present study includes prospective cases of two years from June 2015 to May 2017 and also includes cases from retrospective period (archival of data) of two and half years i.e. - Jan 2013 to May 2015. Thus it includes 130 cases of cholecystectomy specimens during Jan 2013 to June 2017.

- Out of 130 cholecystectomies, 111 $(85.3 \%)$ were laproscopic and 19 (14.7\%) were open laprotomy cholecystectomies.

- Maximum number of patients were in age group of 41-50 years $(26.1 \%)$. 
- Mean age of patient was 50 years. Oldest patient was 80 years, and the youngest was 17 years of age.

- Out of total 130 cases, $69(53 \%)$ were female and $61(47 \%)$ were male.

- In the present study, $96.9 \%$ patients were non-vegetarian and $61 \%$ patients used to have food for 2 times a day only.

- Average BMI of patients in study (26.75 $\mathrm{kg} / \mathrm{m} 2$ ) was higher, which was statistically significant by Odds Ratio (1.21).

- Diabetic patients constitute $13.84 \%$ of total cholecystectomy patients, so diabetes proved to be a risk factor for development of gallbladder diseases with statistically significant Odds Ratio (2.66).

- Out of $20(15.38 \%)$ patients with history of chronic alcohol consumption, pigment stones were present in 12 patients. Positive association of pigment gallstones with history of chronic alcohol consumption was noted in cholecystectomy patients with Odds Ratio of 85.71 .

\section{Conclusions}

Study showed predominance of female patients between age group 41-50 years. Patients with history of diabetes, alcohol consumption, non vegetarian diet pattern and high BMI were found to be affected by gallbladder diseases.

\section{References}

1. Damor NT, Chauhan HM and Jadav HR. Histological study of human gallbladder. International Journal of Biomedical And Advance Research,2013; 04(09): 597-601.

2. Dattal DS, Kaushik R, Gulati A, Sharma VK . International Journal of Research in Medical Sciences, Mar 2017;5(3):840-846.

3. Marschall HU \& Einarsson C. . Gallstone disease. Journal of Internal Medicine 2007;261:529-542.

4. Shabanzadeh DM, Sørensen LT, Jørgensen $\mathrm{T}$. Abdominal Symptoms and Incident Gallstones in a Population Unaware of
Gallstone Status. Canadian Journal of Gastroenterology and Hepatology 2016. Article ID 9730687, http://dx.doi.org/10.1155/2016/9730687:16.

5. Talreja V, Ali A, Khawaja R, Rani K, Samnani SS, and Farid FN . Surgically Resected Gall Bladder: Is Histopathology Needed for All?. Surgery Research and Practice Article ID 9319147, DOI 10.1155/2016/9319147 2016:1-4.

6. Chen YC, Chiou C, Lin MN, Lin CL. The Prevalence and Risk Factors for Gallstone Disease in Taiwanese Vegetarians. PLOS ONE, DOI:10.1371/ journal.pone.0115145 December 2014;1-11.

7. Terada T. . Histopathologic features and frequency of gall bladder lesions in consecutive 540 cholecystectomies . Int J Clin Exp Pathol 2013;6(1):91-96.

8. Pradhan SB, Joshi MR, Vaidya A. Prevalence of different types of gallstone in the patients with cholelithiasis at Kathmandu Medical College, Nepal. Kathmandu Univ Med Journal (KUMJ). 2009 Jul-Sep;7(27):268-71.

9. Sangma MMB, Marak F. Clinicopathological study of acute cholecystitis . Indian Surgery Journal 2016 May;3(2):914-920.

10. Shaffer EA, Small DM. Biliary lipid secretion in cholesterol gallstone disease. The effect of cholecystectomy and obesity. J clin invest. 1977;59:828-840.

11. Festi D, Dormi A et al . Incidence of gallstone disease in Italy: Results from a multicenter, population-based Italian study . World Journal of Gastroenterology 2008 September 14; 14(34): 5282-5289.

12. Khan MR , Raza SA, Ahmad Z, Naeem S, Pervez S , Siddiqui AA, Ahmed M. Gallbladder intestinal metaplasia in Pakistani patients with gallstones. International Journal of Surgery 2011; 9 :482-485 . 
13. Borena W, Edlinger M , Bjørge T, Ggstro $\mathrm{CH}$,Lindkvist B, Nagel $\mathrm{G}$ et al . A Prospective Study on Metabolic Risk Factors and Gallbladder Cancer in the Metabolic Syndrome and Cancer (MeCan) Collaborative Study.PLOS ONE . February 2014;9(2)e89368.

14. Froutan Y, Alizadeh A, FariborzMG , Joukar F, Froutan H , Bagheri FB et al . Gallstone disease founded by ultrasonography in functional dyspepsia: prevalence and associated factors. Int $\mathrm{J}$ Clin Exp Med 2015;8(7):11283-11288 .

15. Mugharbel KM and Al-Mansouri MA.prevalence of obesity among type 2 diabetic patients in Al-Khobar primary health centers. Journal of Family and Community Medicine 2003;10(2):49-53.

16. Cha BH, Lee BS, Lee SH, Kang SJ , Park MJ . A Study of Alcohol Consumption and Obesity as Main Risk Factor for Symptomatic Gallbladder Stone: a CaseControl Study. Asian Pac J Cancer Prev;18 (3):715-719.

17. Schwesinger WH, Kurtin WE, Levine BA, Page CP.Cirrhosis and Alcoholism as Pathogenetic Factors in Pigment Gallstone Formation. Ann. Surg. March 1985:319322.

18. Ugwu AC, Ohagwu CC; Ezeokeke U. The Effect of Moderate Alcohol Intake on Gallblader Motility A Milk Ultrasonographic Study. Libyan J Med 2008. AOP: 080423.

19. Hwang H,Marsh I , Doyle J. Does ultrasonography accurately diagnose Acute cholecystitis? Improving diagnostic accuracy based on a review at a regional hospital. Can J Surg June 2014; 57(3):162168.
20. Chawla A, Bosco JI, Lim TC, Srinivasan $\mathrm{S}$, The HS , Shenoy JN . Imaging of acute cholecystitis and cholecystitis-associated complications in the emergency setting. Singapore Med J 2015; 56(8): 438-444. 